\title{
Entre rituales fúnebres y movilizaciones de protesta. Modos de hacer arte y política durante la última dictadura cívico-militar argentina
}

\author{
Malena La Rocca \\ Instituto de Investigaciones Gino Germani \\ Universidad de Buenos Aires
}

Un sábado por la tarde una comparsa con un muñeco de tamaño humano invadía una concurrida plaza de San Telmo, uno de los barrios más antiguos del sur de la ciudad de Buenos Aires-e invitaba a los paseantes a disfrazarse y sumarse a la fiesta al ritmo de los tambores. En medio de la inusitada verbena el estandarte -que había sido uno de los protagonistas de la celebración- cae al suelo, se acallaron los redoblantes y los cuerpos danzantes se detuvieron. Los participantes del festejo se quitaron el vestuario y en absoluto silencio rodearon al muñeco que quedó sepultado bajo un cúmulo de trapos. ${ }^{1}$

Esta intervención urbana, denominada Marat/Sade, se basó en una investigación realizada por el Tim (Taller de Investigaciones Musicales) sobre fragmentos de la obra teatral Persecución y asesinato de Jean-Paul Marat representado por el grupo escénico del hospicio de Charenton bajo la dirección del señor de Sade, de Peter Weiss. La comparsa también estaba integrada por integrantes del Tit (Taller de Investigaciones Teatrales) y guiada por Marta Cocco, directora de uno de los subgrupos que lo componían.

${ }^{1}$ La reconstrucción de la acción fue realizada a partir del relato de un integrante del Tit, Rubén Santillán, publicado en: Cocco 2017: 85. 
Finalizaba el mes de noviembre de 1981, no era la época de los bailes del carnaval porteño, de hecho durante la dictadura militar (1976-1983) estuvieron prohibidos esos festejos y cualquier otra reunión pública no oficial. A partir del golpe de Estado del 24 de marzo de 1976 que diera inicio al autodenominado Proceso de Reorganización Nacional entraron en vigencia del estado de sitio y la ley marcial que prohibía manifestaciones callejeras y perseguía reuniones de dos o más personas juntas en la vía pública. Una contravención a esta norma podía implicar la detención y el encarcelamiento de quienes la incumplieran. ${ }^{2}$

Contemporáneamente a Marat/Sade en La maravillosa revelación del misterio de Las Brujas, el Grupo de Arte Experimental Cucaño también realizó un ritual de la muerte en el espacio público. Un cortejo fúnebre trasladaba un féretro desde las calles céntricas de la ciudad de Rosario (Provincia de Santa Fe) pasaba por el Monumento Histórico Nacional a la Bandera hasta la cima de las barrancas del río Paraná. Ingresaba a una elegante confitería, un orador proclamaba delirantes discursos sobre las mesas del establecimiento, abría el ataúd y con un cuerpo de yeso en mano declamaba: "aquí está nuestra generación, que también es la de ustedes, una generación muerta, por lo tanto este ataúd les pertenece". Se desplegaba una bandera con la leyenda " ¡Libertad total a la imaginación!" y la procesión religiosa se desperdigaba por las barrancas ante la llegada de las patrullas policiales. ${ }^{3}$

En Marat/Sade y La maravillosa revelación del misterio de Las Brujas fueron desplegaron recursos estéticos para señalar la muerte, los muertos y su perturbador vínculo con los vivos. ¿Cómo interpretar estos rituales fúnebres callejeros realizados durante la dictadura cívico-militar responsable de la desaparición forzada de miles de personas? Si lo leemos desde nuestro conocimiento actual sobre el accionar represivo del régimen estas acciones presentan una inquietante alegoría de que no había encuentro colectivo que pudiera soslayar o evadir las ausencias que intentaba negar la dictadura bajo la anulación de su existencia denominándolos "desaparecidos". ${ }^{4}$ Sin embargo en estas conmemoraciones de la muerte el duelo adquiere una dimensión festiva. La burla carnavalesca no sólo está dirigida hacia la autoridad político-religiosa sino también hacia la juventud, el mismo grupo etáreo de sus actantes. Estas performances

${ }^{2}$ En el Comunicado n.1 y 2 del 24 de marzo de 1976, publicados en el diario "La Razón", p. 4.

${ }^{3}$ Esta acción fue reconstruida a partir de los testimonios de Carlos Ghioldi y Daniel Canale.

4 Ante la presión de la prensa internacional y los organismos de derechos humanos por la desaparición forzada de personas, Jorge Rafael Videla, el jefe de la Junta Militar había declarado: “...frente a los desaparecidos en tanto, éste como tal, es una incógnita. Si reapareciera tendría un tratamiento equis. Pero si la desaparición se convirtiera en certeza, su fallecimiento tiene otro tratamiento. Mientras sea desaparecido no puede tener tratamiento especial, porque no tiene entidad, no está muerto ni vivo". Diario "Clarín” 14 de diciembre de 1979. 
callejeras remitían a mundos sumergidos: el tránsito de la celebración popular al entierro, la parodia alrededor del cadáver-objeto, el llamado a moverse y estar juntos en una fiesta o en una procesión fúnebre. ¿Qué sentidos tendrían para estos colectivos artísticos parodiar la muerte? ¿Era posible quitarle -aunque fuera por un momento a las fuerzas represivas y a las autoridades religiosas- su capacidad de moldear cuerpos y subjetividades? ¿Las acciones artísticas se articulaban con la movilización política?

Con la intención de esbozar respuestas a estos interrogantes he reconstruido la formación de los grupos mencionados para caracterizar su organización y funcionamiento, sus referentes teóricos, sus prácticas artísticas y culturales en diferentes coyunturas de la dictadura militar. ${ }^{5}$ Recurrí a las nociones de "espacio de aparición" de Judith Butler ${ }^{6}$ y a las "formas de carnaval" de Mijaíl Bajtín ${ }^{7}$ para indagar sobre la performatividad de los rituales fúnebres, los usos de la parodia y el llamado a la movilización política en el Tit y Cucaño. Por último, he reflexionado sobre los límites, las tensiones y las reconfiguraciones de las prácticas estéticas y sus vinculaciones con la militancia partidaria y la acción política cuando la dictadura militar entra en un cono de sobras ante el proceso electoral de 1983.

\section{Modos de hacer ARTE Y política en contextos de Violencias de Estado}

Durante la última dictadura militar gran parte de los ciudadanos pasaron a sentirse víctimas potenciales y ante el miedo que generaba el aparato represor, optaron por el silencio y la autocensura. Como señala Avellaneda ${ }^{8}$, desde la dictadura de Juan Carlos Onganía (1966-1970) ${ }^{9}$ existía un fuerte mecanismo de

${ }^{5}$ Las fuentes utilizadas para esta reconstrucción provienen de un trabajo colaborativo con varios investigadores de la Red de Conceptualismos del Sur. Se reunieron más de 300 documentos de los colectivos artísticos referidos, entre correspondencia, minutas internas, cuadernos de trabajo, guiones, programas de mano, afiches, fotografías, negativos, diapositivas, dibujos, fuentes hemerográficas, registros sonoros y audiovisuales entre otros materiales de archivo y 60 testimonios resultado de entrevistas semi-estructuradas de final abierto a integrantes y allegados de los grupos. Una selección de estos documentos está siendo catalogada para que pueda ser consultada en la plataforma Red Conceptualismos del Sur, Archivos en uso, www.archivosenuso.org.

${ }^{6}$ ButLer 2012 [2011].

7 BAJTín 1994 [1965].

8 Avellaneda 1986.

${ }^{9}$ Revolución Argentina es el nombre con el que se autodenominó la dictadura cívico-militar que derrocó al presidente constitucional, Arturo Illia, mediante un golpe de Estado llevado a cabo el 28 de junio de 1966. Este régimen militar no se presentó como provisional sino que pretendió establecerse como un nuevo sistema dictatorial de tipo permanente. La alta conflictividad político-social y las luchas entre los diversos sectores militares produjeron dos golpes internos, 
control sobre la producción cultural y artística en el que participaron tanto organismos estatales (ministerios, secretarías, dependencias policiales) como paraestatales (servicios de inteligencia, fuerzas parapoliciales) y civiles (medios de comunicación e instituciones privadas, etc.). Pero fue a partir de 1976 que este discurso -fundado sobre una intencional ambigüedad- se amplió y sistematizó haciéndolo apto para ser aplicado en cualquier situación según el arbitrio de los funcionarios de turno. Además el accionar de estas organizaciones se dio en el marco de un estado de represión interna donde coexistía una estructura dual de represión legal -las cárceles-e ilegal/paralegal -en los más de 340 centros clandestinos de detención que funcionaron entre 1976 y 1983 a lo largo del país.

Siguiendo a Pilar Calveiro ${ }^{10}$, si el terror se propagó más allá de los límites de los campos de detención y exterminio, su poder y su capacidad de paralizar al conjunto de la sociedad no fueron absolutos. Se produjeron fisuras y alternativas, espacios de negociación, riesgo y confrontación, mutaciones de la acción política. En términos de Brocato ${ }^{11}$, en aquellos años surgieron y/o tomaron mayor visibilidad pequeños espacios de actividad cultural: grupos teatrales, revistas under, talleres literarios, exposiciones de artistas plásticos, que generaron espacios de encuentro y de intercambio alternativos a los que fomentaba el régimen militar y que reunieron algunos átomos dispersados por el embate represivo que no implicaba comportamientos sociales u objetivos políticos deliberados contra el régimen.

Dentro de estas iniciativas culturales (sumamente heterogéneas) inscribo las prácticas estético-políticas del Tit y de Cucaño. El Tit surgió en 1977 en Buenos Aires a partir de una iniciativa de Juan Carlos Uviedo ${ }^{12}$ : fundar un laboratorio abierto de investigación y experimentación dramática, actoral y

sucediéndose en el poder tres dictadores: Juan Carlos Onganía (1966-1970), Roberto Marcelo Levingston (1970-1971) y Alejandro Agustín Lanusse (1971-1973). Acosada por una insurrección popular creciente y generalizada, entre las que se destacaron el Cordobazo y el Rosariazo, la dictadura organizó una salida electoral con participación del peronismo (aunque impidiendo la candidatura de Juan Domingo Perón exiliado después de su derrocamiento en 1955), en 1973, en la que triunfó precisamente el candidato peronista Héctor J. Cámpora quien renunció para permitir nuevas elecciones libres, en las que triunfó Perón con el $62 \%$ de los votos.

10 Calveiro 2008: 117.

11 Brocato 1986: 152.

12 Juan Carlos Uviedo (1939-2009) fue un artista escénico experimental santafesino. Actor, director, escritor, dramaturgo, formó grupos en España, Portugal, EE.UU., Guatemala, México y Argentina que siempre terminaban con la expulsión, deportación, encarcelamiento de Uviedo. En 1977, luego de un intenso periplo por Centro y Norteamérica, Juan Carlos Uviedo fundó el Tit en Buenos Aires. Pocos meses después fue detenido por tenencia de marihuana y, luego de un año de cárcel, se exilió en San Pablo, Brasil. Sobre Juan Carlos Uviedo, puede consultarse: DEBROISE, LONGONI, LA ROCCA 2015. 
escénica para crear colectivamente un montaje teatral. En 1978 el taller porteño continuó -sin su fundador- explorando distintas líneas de experimentación teatral: el absurdo, el surrealismo y el teatro de la crueldad artaudiano. En estrecha relación con el Tit surgieron el Tim en 1978 y el Tic (Taller de Investigaciones Cinematográficas) y el Grupo de la Mujer en 1980.

Mientras que Cucaño se formó en Rosario a fines de 1979 alrededor de unos recitales-happenings organizadas por el músico de jazz Carlos Lucchese, Zapo Aguilera, Alejandro Beretta y un joven poeta Guillermo Giampietro ${ }^{13}$ junto la complicidad de unos cuantos amigos. Luego de las primeras presentaciones varios colaboradores se sumaron al grupo y de la formación inicial solo permaneció Giampietro. En marzo de 1980, Mauricio Kurkbard, un miembro del Tit, organizó en Rosario unos talleres con los integrantes de Cucaño para transmitirles algunas lecturas ${ }^{14} \mathrm{y}$ experiencias de los montajes del grupo porteño. Si bien el intercambio duró solo un par de meses marcó el inicio de una estrecha relación artística, política y afectiva entre ambos colectivos.

Algunos miembros del Tit, TiM, Tic y de Cucaño mantuvieron lazos de afinidad y a la vez de tensión con el Partido Socialista de los Trabajadores ${ }^{15}$ agrupación trotskista que desde 1975 había pasado a la clandestinidad-en relación a la formación de los grupos, la organización interna, sus referentes teóricos y los posicionamientos estético-políticos. Sin embargo el vínculo partidario no era orgánico ni abierto al interior de los talleres, tampoco entre los mismos militantes que por motivos de seguridad mantenían sus contactos políticos de manera independiente y secreta.

${ }^{13}$ Las primeras acciones se realizaron en un festival de arte joven con una banda de música que desarmonizaba el sonido de sus instrumentos provocando incomodidad en los espectadores, en un ciclo de música contemporánea donde en medio del recital aparecían sobre el escenario y entre el público distintos personajes que descontrolaban el lugar, en un balneario de Rosario realizaron una batucada con instrumentos improvisados. Para más información ver: LA RoccA 2012.

${ }^{14}$ Entre los escasos textos que circulaban en aquellos años, debido a los dispositivos de control en las editoriales, librerías y la autocensura discutieron los manifiestos surrealistas de André Breton, trabajaron la teoría teatral a partir de: Antonin Artaud, Vsévolod Meyerhold, Jerzy Grotowski y Peter Brook; a los poetas malditos como el Conde de Lautréamont y Arthur Rimbaud y las novelas y dramaturgia de Jean Genet y Eugène Ionesco, entre otros. Testimonio de Guillermo Giampietro 2011.

${ }^{15}$ Agrupación de izquierda crítica a la lucha armada que surgió en 1972 de la fusión de Prt (Partido Revolucionario de los Trabajadores) - La Verdad junto a una corriente del Partido Socialista Argentino liderada por Juan Carlos Coral con una destacable influencia en el movimiento obrero y sindical. Durante la última dictadura cívico-militar el Pst fue proscripto, sumido a la clandestinidad y sus cuadros dirigentes se exiliaron en Colombia. Entre 1974 y 1982 fueron fusilados 16 militantes por parte de la Triple A, fueron desaparecidos 80 de sus miembros y 30 militantes fueron presos “a” disposición del Poder Ejecutivo Nacional”. Osuna 2015. 
Los grupos se constituyeron como pequeñas comunidades ${ }^{16}$ que funcionaron de manera autogestiva -a partir de la venta de sus publicaciones ${ }^{17}$, entradas de los montajes, rifas y bonos contribución- y de formación colectiva en talleres (de teatro, música, cine, historieta) y grupos de lectura. Los montajes y las fiestas no eran abiertamente públicos, los difundían de boca en boca y se accedía por invitación personal de algún conocido del grupo. Dentro de los subgrupos de teatro se impulsaba a que los integrantes se animaran a construir otras líneas de investigación, que crearan sus propios grupos y montajes. De esta manera lograron ampliar los círculos de colaboradores y allegados a los talleres. El uso de pseudónimos, el cambio periódico de sitios donde desarrollaban sus actividades y presentaciones (desde salas teatrales, clubes de barrio, distintas casonas que alquilaron), la organización en grupos de afinidad en base a una estructura piramidal, la autogestión, eran conocimientos adquiridos en la militancia que trasladaron a los talleres para protegerse de la represión militar y obtener recursos para funcionar.

Estos colectivos instaron -a través de sus manifiestos, talleres, publicaciones y en la realización de fiestas, peñas y festivales- a conformar un movimiento, que aglutinara redes de artistas alternativos al mercado y a la política cultural que dictaba el régimen. El primero -denominado el Zangandongo- surgió en 1979 por iniciativa del Tit y organizó en Buenos Aires el festival Antiproarte Alterarte I. ${ }^{18}$ La segunda edición del festival Antiproarte Alterarte $\mathrm{II}^{19}$ tuvo lugar en agosto de 1981 en San Pablo, Brasil. Fue organizada por un grupo del Tit que desde un año antes se había instalado en aquella ciudad y dio origen

${ }^{16}$ A partir de las entrevistas se pudo reconstruir que alrededor del TiT participaban 150 personas entre sus talleres y el público de sus montajes, en Cucaño era notablemente más pequeña no superaban las 50 personas.

${ }^{17}$ El TiT publicó el folletín del Zangandongo (1979), El Zangandongo no es un bicho (1980), El Zangandongo vuelve. Cuaderno 1 (1980), el boletín Juego 26. Todos contra todos (1980). Mientras que las publicaciones de Cucaño fueron: Acha, acha Cucaracha (1980), El Maldito Chocho (1981) y Aproximación a un hachazo (1982). Ambos grupos participaron en la edición de Enciclopedia Surrealista (1981) del Movimiento Surrealista Internacional.

${ }^{18}$ En Alterarte I reunieron a decenas de artistas de varias generaciones (desde la vanguardia concreta de los años cuarenta, la vanguardia de los sesenta y el activismo teatral de la última dictadura). Se realizaron presentaciones plásticas, dramáticas, musicales entre el 20 de noviembre y el 8 de diciembre de 1979, en el Teatro Del Plata, una sala céntrica a pocos pasos del Obelisco porteño. En el periódico Clarín del 23 de diciembre de 1979 fue publicada una breve reseña del festival.

${ }^{19}$ Alterarte II tuvo lugar del 11 al 20 de agosto en la Facultad de Arquitectura y la Escuela de Comunicación de la Universidad de San Pablo. Se realizaron charlas debates sobre la juventud, el rol de la mujer en la producción artística, el surrealismo, el cine experimental y el teatro de calle, se hicieron proyecciones de cine clásico y experimental (Mac Laren, Godard y Buñuel), presentaciones de recorridos de artistas plásticos, performances e intervenciones. (En balances de Alterarte II y Afiches del festival, fechados agosto de 1981). 
a la fundación del Movimiento Surrealista Internacional - $\mathrm{Msi}^{20}$ - en el que participaron el Tit Buenos Aires y San Pablo, el Tim, el Tic, Cucaño y el colectivo paulista Viajou sem Passaporte (Vsp). El acróstico Sit condensaba las consignas del movimiento: subvertir, intervenir y transgredir con sus acciones artísticas la vida cotidiana de sus ciudades.

A partir de los cuadernos de ensayos ${ }^{21}$ de los grupos pude reconstruir que en sus talleres teatrales trabajaron intensamente la preparación física sobrepasando el límite del agotamiento corporal e incentivaron el desarrollo actoral desde la capacidad de provocación realizando juegos creativos, movimientos plásticos e improvisaciones. En paralelo investigaron teóricamente sobre distintas temáticas (el absurdo, lo siniestro, la decadencia social, la locura, la caza de brujas) las debatieron y tradujeron en ejercicios de trabajo corporal y textos de escritura automática. También realizaron ejercicios en la calle que incluían desde la observación de comportamientos y reacciones sociales cotidianas, experimentando qué efectos suscitaban en los transeúntes en la vía pública si se empleaban ciertos objetos, gestos y movimientos que discutían y podían incorporar en sus acciones artísticas. Sus montajes teatrales e intervenciones urbanas $^{22}$ eran de creación colectiva y estaban diseñados a partir de bloques o guiones que solo tenían indicaciones mínimas. El director o provocador iba señalando el ritmo y la secuencia de las acciones que tenían un desenlace inesperado para todos los presentes. En las puestas como en las acciones callejeras no estaba delimitado el espacio escénico, los actores aparecían y se esfumaban entre los espectadores o los transeúntes. El cuerpo semi-desnudo, cubierto con trapos o vestido con ropa de ensayo, el despliegue de sus movimientos físicos

${ }^{20}$ El Msi fue el resultado de acuerdos previos entre los grupos como el acuerdo de San Pablo fue firmado por el TiT y Vsp en febrero de 1980 y adherido por Cucaño en mayo del mismo año. Consistía en nueve puntos en común para "formar un movimiento artístico latinoamericano para la revolución del arte". Allí expresaban: "Luchar a botellazos contra todas las formas de realismo y didactismo de mensajes", "investigar hasta las últimas consecuencias las relaciones inherentes a la actividad creadora: artista, público, medios; sin que compromisos exteriores interfieran en dicha investigación" que implicaría la libertad total al arte sin limitarlo a la política partidaria, ni a la censura. También se proponían organizar movimientos para intervenir en la vida cultural, luchar contra la actividad artística como mercancía y la creadora como obra, destacando su compromiso con la liberación total del hombre. En Acuerdos de San Pablo, mímeo, 1980.

${ }^{21}$ Los tres cuadernos de ensayo de Cucaño están fechados en 1980 y 1981, distintos integrantes de Cucaño oficiaban de apuntadores. Los cuadernos del Tit pertenecen al Chulu son de 1978 y están publicados en: Cocco 2017.

${ }_{22}$ Mientras que los montajes o hechos artísticos (que podían ser teatrales, musicales o plásticos) los presentaban en salas, clubes de barrio o en sus propios espacios que denominaban casonas, las intervenciones eran prácticas callejeras, anónimas y por lo tanto los transeúntes -que ignoraban su condición de espectadores- se convertían en público en la medida que se sintieran interpelados por la acción. 
y acrobáticos, la voz declamando discursos, recitando poesías, ensamblándose con otras para formar coros o que tan sólo emite sonidos, la palabra tomada de fragmentos de obras literarias, poesías, discursos políticos o mediáticos, publicidad o de textos en lenguaje inconexo, ensamblada como un cadáver exquisito eran recursos comunes que circularon en los talleres para sus producciones.

"Vivíamos exaltados"23 expresó una integrante del Tit para describir sus prácticas estético-políticas. Esta frase sintetiza una "estructura del sentir" en términos de Raymond Williams ${ }^{24}$ que nos permite comprender cómo los miembros del TiT elaboraron maneras de crear e intervenir colectivamente en medio de una atmósfera de parálisis, desconfianza, miedo generalizado, de crisis y de terror, elementos de una tecnología de poder que la última dictadura cívico-militar hábilmente operó sobre gran parte de la sociedad. Sin embargo, el estar en la vida de manera desbordada, no era solo improvisar, desobedecer, transgredir, "vivir exaltados" se enlaza contradictoriamente con el discurso que lo nombra. Esto se condensa en "hay mucho pero no se puede" frase que según recuerda Silvina Epstein ${ }^{25}$-otra integrante del Tit- coreaban al finalizar sus acciones, un grito de libertad que quedaba atragantado por el miedo intermitente en medio de un espacio público clausurado en el que operaban los fantasmagóricos efectos de los dispositivos de control propios del terrorismo de Estado.

\section{Rituales De LA MUERTE EN EL ESPACiO PÚBlico}

Los rituales de la muerte en Marat/Sade y en La maravillosa revelación del misterio de Las Brujas transformaron el duelo en una movilización colectiva y en una ocupación momentánea del espacio público. Siguiendo a Judith Butler:

El cuerpo que se crea entre aquellos que actúan juntos, el espacio de encuentro, es un espacio de presentación. Esos cuerpos excluidos sin derecho legal a estar ahí, están expresando su oposición a la legitimidad del Estado, lo que hacen ante la ocupación del espacio es repetir esa ocupación y persistir en la misma, planteando un desafío en términos corporales, lo que significa que cuando el cuerpo habla políticamente no sólo

${ }^{23}$ La frase había surgido en una entrevista realizada por Ana Longoni a Irene Mozskowski (2012) y fue retomada en la entrada "Arte revolucionario" en: Red ConCEPTUALiSMOS DEL SuR 2012: 62. La frase resurgió en un conversatorio de artistas a propósito del Seminario internacional Perder la forma humana. Conversaciones sobre arte y politica en los años 80 en América Latina que tuvo lugar el 6 de junio de 2014 en el Centro Cultural Borges de la Ciudad de Buenos Aires y fue recuperada en el prólogo que escribí para el libro de Cocco 2017.

${ }^{24}$ WiLliams 1988 [1978]: 151.

${ }^{25}$ Entrevista a Silvina Epstein realizada por Ana Longoni en Madrid (18 de diciembre de 2011). 
lo hace de manera oral o escrita. Al hacerlo a través de la performatividad del cuerpo sobrepasa el lenguaje. Cuando la legitimidad del Estado se cuestiona por las formas de aparecer en público, el cuerpo en sí ejerce un derecho que no es un derecho; es decir ejerce un derecho que ha sido combatido y destruido de forma activa por la fuerza militar y en su resistencia a esa fuerza, articula su permanencia y el derecho a la misma. ${ }^{26}$

Así al apoderarse de los espacios y rituales establecidos y permeados por el poder existente, busca resquebrajar la relación entre espacio público, la plaza pública y el régimen. Pero esta ruptura no se generó a través de una confrontación directa con el régimen.

Con La maravillosa revelación del misterio de Las Brujas Cucaño concluyó Las Brujas. Dos meses de surrealismo y transgresión, una serie de intervenciones urbanas y montajes teatrales realizadas entre septiembre y noviembre de 1981 por el colectivo rosarino con la intención de alterar la normalidad cotidiana de la ciudad. Entre las múltiples acciones realizadas, Daniel Canale, uno de sus integrantes recuerda que los parques amanecían atiborrados de volantes con palabras y dibujos incoherentes, los bancos con plumas pegadas y la pintada "Libertad total a la imaginación", en las paredes lindantes, completaban la escena. Una decena de jóvenes saltaba al rango ${ }^{27}$ a lo largo de una calle peatonal interrumpiendo el paso de quienes caminaban por el centro de la ciudad. Horas más tarde, hacían movimientos biomécanicos en ronda en los pasillos de una galería comercial ante la mirada atónita de los paseantes. Por las noches, una cuadrilla de oradores entraba furtivamente en los bares proclamando su manifiesto del "arte bobo". Un domingo a la tarde en un parque muy concurrido de Rosario, entre mates y bizcochitos, se rumoreaba que un actor internacional estaba de visita en la ciudad, de repente bajaron de un auto un hombre de cabellos rubios con gafas con guardaespaldas, inmediatamente aparecieron periodistas, la gente se les abalanzaba para conseguir un autógrafo. En ese preciso momento el actor y los reporteros se retiraban de la plaza reptando como amebas.

Tomando como metáfora la caza de brujas en la Edad Media y estudiando un manual de la Inquisición, Cucaño evocó el emblema de la subversión para la modernidad, aquel que desde fines de la década del ' 60 en diferentes puntos del planeta, había encarnado por antonomasia la juventud. Los integrantes de Cucaño, que eran pocos años menores de la generación que había sido

26 ButLer 2012 [2011]: 95.

${ }^{27}$ Se trata de un juego infantil en el que los participantes se disponen en fila separados por un par de metros se inclinan a la altura de la cintura como si fueran una mesa, uno de ellos se impulsa con las manos en la espada del compañero inclinado para pasarle por arriba. De esta manera va saltando uno a uno y se ubica al final de la hilera. Quien quedó primero realiza la misma acción y así la fila se desplaza en conjunto. 
directamente aniquilada por la dictadura, generaron elípticamente una confrontación en la que homologaron al status de "cadáveres" - el resto del cuerpo humano tras la muerte- a los jóvenes que se mostrasen anuentes, conformistas, acomodaticios o simplemente obedientes ante el disciplinamiento impuesto por el régimen militar y sus colaboradores.

Lucena señala que la última dictadura militar argentina se ocupó especialmente de delimitar y regular los rasgos de la estética adecuada y deseable para los jóvenes, quienes se presentaron como el blanco privilegiado de las acciones "moralizantes" del gobierno militar en su intento por regular conductas, vigilar acciones y prevenir posibles "desviaciones". ${ }^{28}$ Todo aquel que escapase a las normas y valores conservadores y autoritarios propuestos por la dictadura sería considerado anormal/enfermo y articulado en la serie de significantes anormalidad-enfermedad-peligro. Esto había adquirido en Rosario ribetes represivos insólitos, por ejemplo, Águila señala que una contravención a las buenas costumbres eran las demostraciones de afecto en el espacio público ${ }^{29}$, como es el caso de las parejas que se besaban en las plazas, la persecución a los jóvenes que se ausentaban de sus clases escolares y deambulaban por los paseos públicos como también aquellos que veían fumando. Los guardianes de la moral y las buenas costumbres que operaban en una ciudad del interior (al igual que quienes lo hacían en la capital del país), buscaban disciplinar una sociedad considerada "menor de edad" protegiéndola del contacto de libros, revistas, películas, obras de teatro, músicos que juzgaban perniciosos en su cruzada de defensora de los valores cristianos occidentales. Cucaño se apropió de la imagen infantil que el poder había construido sobre la sociedad; si bien sus inocentes acciones parecían juegos, idioteces de adolescentes, perturbaban el ordenamiento cotidiano, al tensionar los ambiguos y porosos márgenes de lo que no era sancionable o sancionado aún por las fuerzas represivas. Con Las Brujas Cucaño parodió el imaginario del poder sobre la sociedad, entendiendo la parodia a partir de Agamben como la "imitación del verso del otro en el cual aquello que en otros es serio se vuelve ridículo o cómico". ${ }^{30}$

La apelación a la juventud no sólo se daba en clave paródica. El programa de mano de Lágrimas fúnebres, pompas de sangre, un montaje del grupo porteño afirma: "Nuestra generación desviada, abandonada, adormecida, aplastada, reventada, agonizante, asesinada, es la doble protagonista de un funeral donde yace y observa al mismo tiempo". ${ }^{31}$ A partir de esta frase se complejizaba el enfrentamiento social en términos orden/subversión que la dictadura militar fo-

\footnotetext{
28 LUCENA 2011.

29 Águila 2008: 238-239.

30 Agamben 2005: 47.

${ }^{31}$ LONGONI 2012: 42.
} 
mentaba. Según el Tit, la juventud era objeto de una pedagogía de poder de un régimen represivo que no sólo desaparecía personas, sino que -como proponen Gociol y Invernizzi ${ }^{32}$ - buscaba erradicar ideologías, símbolos y valores.

\section{LA CRÍTICA ESTÉTICA COMO PARODIA}

"... el teatro no es el reflejo de la realidad sino la realidad de un reflejo" comenzaba el programa de mano de La insurrección de las liendres (Poema Épico) ópera bufa desarrollada durante la II muestra de Teatro Rosarino ${ }^{33}$ en diciembre de 1981 con la que Cucaño se presentó como un grupo de teatro. Según recuerda Carlos Ghioldi ${ }^{34}$, la obra comenzaba con una escena melodramática entre un joven de una villa miseria que se enfrentaba a su padre porque había dejado a su novia embarazada pero finalmente se reconciliaban estrechándose en un abrazo. Al finalizar la escena, un hombre corriendo pedía a gritos que se desalojase el teatro de manera urgente porque en la ciudad había una terrible insurrección de liendres que querían tomar el poder. En la calle se acercaban diecisiete hombres-liendres arrojando panfletos y arengando a los espectadores a que ingresaran nuevamente al teatro. A lo largo de las dos escaleras que desembocaban en la sala varios de los hombres-liendres se ahorcaban, otro pedía auxilio.

El Tit no había sido invitado al II Encuentro de las $\operatorname{Artes}^{35}$, si bien había participado en la primera edición, rememoraba Marta Cocco y relata que durante un intervalo del festival actores del Tit irrumpieron en la sala: abrieron las puertas de par en par y marchar como en una procesión religiosa. Cuando las luces del teatro se encendieron, desplegaron banderas y pancartas transformando la procesión en una movilización política. Recitaban un discurso: "En el acto cargado de solemne teatralidad, al cumplirse nuevamente indistintamente ordenado en el tiempo el entierro de la juventud. Rescatando la representación y su

32 Gociol, InVernizzi 2002: 109.

${ }^{33}$ La muestra estaba organizada por la Federación Argentina de Grupo de Teatro (FAGT) y se realizó en la Sala Mateo Booz del 3 al 15 de diciembre de 1981. En el diario rosarino "La Capital" el 14 de diciembre de 1981 se publicó una reseña del evento.

34 Testimonio de Carlos Ghioldi en base al cual se reconstruyó la acción, en: ARIAS, RODRÍGUEZ, TOMÉ 2003: 23.

${ }^{35}$ Festival independiente organizado por la agrupación trotskista Pst. La primera edición se realizó entre el 10 y el 20 de noviembre de 1980 en el Teatro Picadero, mientras que la segunda se realizó el 15 de noviembre de 1981 en el Teatro Margarita Xirgu de la ciudad de Buenos Aires. Según recuerda Sava -que participó en ambas ediciones- "El Encuentro de las artes, por encima de las rupturas conceptuales y formales del teatro era más bien un encuentro político, se convocaba a gente que estuviera en una línea de avanzada del teatro pero no necesariamente tenía que haber rupturas estéticas. Más bien era una convención de artistas comprometidos en luchar contra la censura. Entrevista a Alberto Sava realizada por Ana Longoni y Lorena Verzero, 2013. 
juego mentiroso, ipedimos un minuto de silencio!", ${ }^{36}$ y desde los palcos tiraban mariposas con consignas libertarias. En minutos una lluvia de papeles cubrió el teatro al compás del bolero de Ravel -finalizó la directora del Tit. ${ }^{37}$

Con estas dos intervenciones los grupos pusieron de manifiesto la tensión entre el adentro y el afuera del teatro a partir del recurso de la parodia. Detrás del tema de la Revolución Rusa y la anécdota de la toma del palacio de invierno, Cucaño encubría una burla a los demás grupos de teatro. ¿En qué consistía la burla? Según relatan los integrantes del grupo planeaban que el primer acto de su intervención fuese la obra del reconocido grupo Arteón ${ }^{38}$ que los antecedía. Pero como este no se presentó la recrearon ellos mismos, improvisando una escena melodramática en una villa miseria. El objetivo era incitar a que los espectadores fuesen quienes pasaran a la acción y así hacer estallar la farsa de los otros conjuntos de teatro que a través de sus obras buscaban transmitir mensajes éticos a la sociedad. A partir de esta sátira realizaron una demostración política cuya mira estaba puesta en el medio cultural rosarino independiente. El uso que hicieron del adentro y el afuera de la sala, las alternancias entre la unidad teatral y el quiebre que produjeron en la simultaneidad de la acción, daban cuenta de la reinvención de formas de intervención para generar antagonismo con respecto a las prácticas hegemónicas/convencionales del "arte comprometido" que asociaban a la estética del realismo.

En ese sentido entiendo estas acciones como gestos de desacralización del teatro en general y de aquel que se pretende político en particular. Intervinieron ante el público de esas obras utilizando lenguajes propios de la movilización político-partidaria (corporales, gestuales, de objetos y performativos) e interpelaron al espectador para que participase de una acción política desplazando las porosas fronteras entre ficción y realidad. Sin embargo "gran parte del público aplaudía y no se levantaba de las butacas, no entendían la burla" - señaló Daniel Canale ${ }^{39}$, uno de los hombres-liendres de Cucaño, "en otros casos aceptaron el espectáculo como simple juego visual, acústico y corporal” reflexionó

${ }^{36}$ Cocco 2017: 87.

37 Cocco 2017: 87.

${ }^{38}$ Logiódice y Di Filippo reconstruyeron la historia de Arteón que se formó como un colectivo de experimentación audiovisual y teatral formado en Rosario en 1968. LoGióDice, Di FILIPPO 2015. En 1971 decidieron sumarse a la Juventud Peronista desde su quehacer escénico tomando la doctrina justicialista como insumo para sus obras. Néstor Zapata, director del grupo, fue partícipe y fundador de entes gremiales de actores y afines al peronismo. A pesar de la prohibición de la actividad gremial durante la dictadura siguieron funcionando como entidades culturales promoviendo los intercambios entre los elencos de las provincias y encuentros teatrales. El grupo Arteón estableció su propia sala y logró crecer en medio de la censura y control por parte de la Comisión Calificadora de Espectáculos Públicos.

39 Entrevista realizada a Daniel Canale por Malena La Rocca, Ana Longoni y Jaime Vindel (11 de julio de 2011). 
Carlos Ghioldi dando cuenta el clima de efervescencia social que se vivía aquel fin de año.

De hecho parte del grupo se había tornado más escépticos hacia la capacidad transformadora del arte y parecía reorientarse hacia la praxis política "la transgresión parece absurda y pueril si ella no ayuda al surgimiento de un nuevo estado de cosas, en el cual ella ya no sea necesaria" expresaron en una Carta al Movimiento Surrealista Internacional, fechada a fines de diciembre de 1981.

\section{RECONFIGURACIONES POLÍtICAS}

En marzo de 1981 Roberto Viola sucedió a Jorge Rafael Videla que había permanecido al frente de la Junta Militar desde 1976. Canelo apunta que durante la gestión del primero, más aperturista, eclosionaron las contradicciones políticas latentes al interior del régimen profundizadas por la presión internacional de los organismos de derechos humanos, la crisis económica, la convocatoria de la dirigencia sindical a la segunda huelga nacional desde 1976, la conformación de una Asamblea Multipartidaria con las agrupaciones políticas mayoritarias y el episcopado para presentar un cronograma de transición a la democracia ${ }^{40}$

Desde la rendición argentina en la Guerra de Malvinas, el 14 de junio de 1982, la salida democrática se aceleró y la agitación política y social creció exponencialmente. Con el regreso a la militancia pública se intensificó la actividad de los partidos políticos teniendo como horizonte las elecciones democráticas del 30 de octubre de 1983.

En 1982 la mayoría de los integrantes del Tit, Tim, Tic y Cucaño se abocaron a la militancia en la juventud del PST (para ese entonces reconvertido en Mas - Movimiento al Socialismo) ${ }^{41}$, abandonaron sus prácticas artísticas y los grupos se disolvieron. Compartieron con el líder del partido, Nahuel Moreno, la caracterización de que la derrota argentina en la Guerra de Malvinas había desatado la crisis económica y política al interior del régimen cívico-militar y se estaba ante una coyuntura revolucionaria. También coincidían en la necesidad histórica de construir el partido revolucionario de masas, el Mas.

Si interpretamos las relaciones entre estos grupos artísticos y las organizaciones partidarias en una secuencia lineal o de retorno cíclico bajo la primacía de la acción política se podría leer el itinerario del Tit y Cucaño como la adaptación de un grupo de militantes ante la interrupción en la vida institucional que

40 Canelo 2008: 171.

${ }^{41}$ Organización política trotskista fundada en 1982 por Nahuel Moreno, continuadora de la línea del Pst. Luego de la muerte de Nahuel Moreno, en 1987, el Mas se fraccionó en varios partidos políticos que se inscribieron en la corriente trotskista-morenista. 
implicó la última dictadura cívico-militar argentina. Pero entender la dictadura como paréntesis o como tiempo político en suspenso reduce la comprensión de procesos de subjetivación más complejos y sutiles que se gestaron en esos años $y$ que han tenido efectos y resonancias menos inmediatos.

A partir de las experiencias del Tit y de Cucaño podemos inferir que cuando las estructuras partidarias fueron ilegalizadas en 1975, las formas de organización clandestinas de la militancia y la renovación constante de la experimentación teatral se entrelazaron, se citaron y se contagiaron, resultando estéril e improductiva su disociación. En el despliegue y reiteración de sus prácticas artísticas callejeras pusieron en evidencia los márgenes, los intersticios y tensionaron los límites en los que se podía llevar a cabo una acción colectiva, cómo se podían eludir (hasta poner en ridículo) las estrictas reglamentaciones del espacio público y la censura, aún cuando estaba vigente el estado de sitio. De esta manera, mediante el uso de metáforas, lo grotesco, la parodia, los movimientos del cuerpo, el espacio y la disposición de los objetos -entre otros recursos artísticos- fueron modulando maneras de expresarse y de intervenir en la vida cotidiana de las ciudades sin confrontar directamente con el régimen. El cuerpo y la ciudad, lugares privilegiados de emplazamiento del disciplinamiento militar emergieron como soporte de las acciones artísticas, como espacio de transgresión de las normativas sociales, de experimentación con otros, de fiesta y de goce, exaltando lo absurdo de estar vivos durante aquella coyuntura de violencias políticas. Una estrategia que generaba disenso, en términos de Rancière ${ }^{42}$, ya que cambiaba los modos de presentación sensible al modificar las formas de enunciación y construir relaciones nuevas entre apariencia y realidad o entre lo visible y su significación. Pero este disenso evidentemente contrastaba con las maneras de construcción política partidaria del Mas y con las tareas previstas para la militancia partidaria. Daniel Canale recuerda que el Partido les planteó la disyuntiva entre la actividad artística y política arguyendo que sus acciones callejeras finalizaban cada vez más frecuentemente con detenciones policiales.

En paralelo -siguiendo el planteo de Osuna ${ }^{43}$ - el discurso político del Partido trotskista se fue moderando de cara al proceso electoral de 1983, enfatizando más en el "socialismo democrático" de corte parlamentarista y alejándose de los fundamentos del "socialismo revolucionario". ${ }^{44}$

${ }^{42}$ Rancière entiende la eficacia estética como una distancia entre la intención del artista, los recursos que utiliza, la mirada del espectador y el estado de una comunidad y distingue entre el consenso que se produce cuando existe continuidad entre percepción y significado y el disenso que generaría un choque entre dos regímenes de sensorialidad que modifica las coordenadas de lo representable. RANCIÈRE 2010 [2008]: 67.

43 OSUNA 2015.

44 OSUNA 2015: 163. 
Si bien estos colectivos artísticos se habían conformado como territorios de amplias libertades creativas, también lo fueron de coerciones y arbitrariedades que se fundaban en la organización de los grupos bajo estructuras de poder piramidal. ${ }^{45}$ Se produjeron oscilaciones, fricciones y matices entre distintas posturas de los integrantes de los grupos en relación a los vínculos entre arte y política: quienes defendieron un ethos militante revolucionario de izquierdas y consideraron las prácticas culturales como forma de canalizar las energías políticas durante la dictadura; quienes reivindicaron la contracultura como agente de la transformación social asociando la libertad en la creación artística, a la locura, la marginación social.

Desde esta perspectiva considero que la última dictadura no fue en términos culturales una tábula rasa, ni generó una ruptura total en relación al periodo previo sino que se trató de un periodo de colapso social y complejas resignificaciones culturales sobre las que este escrito intentó avanzar y seguiré indagando.

\section{BiBLIOGRAFÍA}

Agamben 2005 - G. Agamben, Profanaciones, trad. F. Costa, E. Castro, Buenos Aires 2005. [Profanazioni, 2005]

Águila 2008 - G. Águila, Dictadura, represión y sociedad en Rosario, 1976/1983, Buenos Aires 2008.

Arias, Rodríguez, Tomé 2003 - A. Arias, A. Rodríguez, A. Tomé (editores), Cucaño: Surrealismo y transgresión en Rosario, "Revista de Retrospectiva teatral Señales en la Hoguera", a.II, n.5, 2003.

Avellaneda 1986 - A. Avellaneda, Censura, autoritarismo y cultura: Argentina 1960-1983, Buenos Aires 1986.

BAJTín 1994 [1965] - M. Bajtín, La cultura popular en la Edad Media y en el Renacimiento, trad. J. Forcat y C. Conroy, Buenos Aires-Madrid 1994. [Tvorchestvo Fransua Rable i narodnaia kul'tura srednevekov'ia i Renessansa, 1965]

${ }^{45}$ La seguridad habilitaba comportamientos de extrema censura entre los integrantes de $\mathrm{Cu}$ caño, como de echar integrantes por no cortarse el pelo, o por ser expulsados del colegio (HULTEN 2010: 67) o de hacer espionaje ante la sospecha del uso indebido de la casona que en otras palabras era usar el espacio para mantener relaciones sexuales con sus parejas. En definitiva aquello que se dirimía detrás argumentos morales, estéticos u organizativos era una disputa por el poder, el liderazgo y la dirección del grupo. Como contrapunto para el TIT San Pablo, esa moral ascética era desestimada y en contraposición el lumpenaje era adoptado como forma de vida. 
BUTLER 2012 [2011] - J. Butler, La alianza de los cuerpos y la política de la calle, trad. R. Martínez Dávila, "Debate Feminista", vol. 46, 2012, pp. 91-113. [Bodies in Alliance and the Politics of the Street, 2011]

Brocato 1986 - C. Brocato, El exilio es nuestro. Los mitos y los héroes argentinos. ¿Una sociedad que no se sincera?, Buenos Aires 1986.

Calveiro 1998 - P. Calveiro, Poder y desaparición. Los campos de concentración en Argentina, Buenos Aires 1998.

CANelo 2008 - P. Canelo, El proceso en su laberinto. La interna militar de Videla a Bignone, Buenos Aires 2008.

Cocco 2017 - M. Cocco, Taller de Investigaciones Teatrales. Acción política y artística durante la última dictadura argentina, Buenos Aires 2017.

Debroise, Longoni, La Rocca 2015 - O. Debroise, A. Longoni, M. La Rocca, Con la provocación de Juan Carlos Uviedo, México 2015.

Gociol, INVERNIZZI 2002 - J. Gociol, H. Invernizzi, Un golpe a los libros: Represión a la cultura durante la última dictadura militar, Buenos Aires 2002.

Hulten 2010 - C. Hulten, Prácticas artísticas de resistencia a través de la acción dramática durante el proceso militar en Rosario: el caso de Cucaño (1979-1983), tesis de Licenciatura en Bellas Artes por la Universidad Nacional de Rosario, Rosario 2010.

LA Rocca 2012 - M. La Rocca, El delirio permanente. El Grupo de Arte Experimental Cucaño (1979-1984), tesis de maestría en Investigación en Humanidades, Universidad de Girona (España), Girona 2012.

La RocCa 2013 - M. La Rocca, El Grupo de Arte Experimental Cucaño. Intervenir el espacio, transgredir las prácticas artístico-politicas, "Separata", a.XII, n.17, diciembre de 2013, pp. 21-33.

LoGióDice, Di FILIPPo 2015 - M. J. Logiódice, M. Di Filippo, De la militancia a la institucionalización. La experiencia de Arteón en los 70, “Telón de fondo", n.22, 2015, pp.1-13, http://revistascientificas.filo.uba. ar/index.php/telondefondo/article/view/2151.

LONGONI 2012 - A. Longoni, Zona liberada. Una experiencia de activismo artístico en la última dictadura, "Boca de Sapo", n.12, 2012, pp. 46-51.

LoNGONI 2014 - A. Longoni, Vanguardia y revolución. Arte e izquierdas en la Argentina de los sesenta-setenta, Buenos Aires 2014.

LuCENA 2011 - D. Lucena, Guaridas underground para Dionisios, en: CCEBA - CIA - Red Conceptualismos del Sur, Cuerpos desobedientes. Nuevos cruces entre arte y politica en América Latina en los años 80, seminario, Buenos Aires 2011.

Osuna 2015 - M. F. Osuna, De la "Revolución socialista" a la "Revolución democrática”: Las prácticas del Partido Socialista de los Trabajadores/ 
Movimiento al Socialismo durante la última dictadura (1976-1983), La Plata 2015.

RANCIÈRE 2010 [2008] - J. Rancière, El espectador emancipado, trad. A. Dilon, Buenos Aires 2010. [Le spectateur émancipé, 2008]

Red Conceptualismos del Sur 2012 - Red Conceptualismos del Sur, Perder la forma humana. Una imagen sísmica de los años ochenta en América Latina, Madrid 2012.

WiLliams 1988 [1978] - R. Williams, Marxismo y literatura, trad. P. di Masso, Barcelona 1988. [Marxism and Literature, 1978]

\section{Testimonios}

Entrevista a Alberto Sava realizada por Ana Longoni y Lorena Verzero, 11 de julio de 2013.

Entrevista a Marta Cocco realizada por Ana Longoni, 11 de diciembre de 2011. Entrevista a Mauricio Kurkbard realizada por Ana Longoni, Malena La Rocca y Lorena Verzero, 12 de abril de 2012.

Entrevista realizada a Daniel Canale por Malena La Rocca, Ana Longoni y Jaime Vindel, 21 de julio de 2011.

Entrevista a Silvina Epstein realizada por Ana Longoni, 15 de diciembre de 2011.

Entrevista a Irene Mozskowski realizada por Ana Longoni, 4 de mayo de 2012. Entrevista a Gloria Rodríguez realizada por Malena La Rocca, 10 de agosto de 2011.

Entrevista a Roberto Barandalla realizada por Ana Longoni, 6 de junio de 2011. Entrevista a Carlos Ghioldi realizada por Ana Longoni y Jaime Vindel, 10 de junio de 2011.

Entrevista a Marcelo Roma realizada por Malena La Rocca, 9 de agosto de 2011.

Entrevista a Luis Alfonso realizada por Malena La Rocca, 10 de agosto de 2011.

Testimonio de Guillermo Giampietro, 31 de agosto de 2011.

Testimonio de Guillermo Giampietro, publicado en Arias, Rodríguez, Tomé 2003.

Testimonio de Carlos Ghioldi, publicado en Arias, Rodríguez, Tomé 2003. 


\section{Summary}

\section{Between funeral rituals and protest mobilizations. Methods of engaging in art and politics during the last civilian-military Argentinian dictatorship}

Within my research on activism and theatre experiments in the latest Argentine history, I wonder about ways of engaging in art and politics during the last civil-military dictatorship in 1976-1983. For this purpose, I focused on the aesthetic and political activity of Tit (Taller de Investigaciones Teatrales) and Cucaño: two artistic groups formed during this period in Buenos Aires and Rosario respectively. Their undertook activities in the repressive conditions that marked everyday life in the times of state terrorism. However, members of both groups, who conducted bold street actions, organized theatre gatherings and festivals and published the fanzine, which referred to a specific form or rhetorical discourse, not always aimed at direct confrontation with the regime. The article discusses funeral rituals that were present in the artistic activities of both groups. It also allowed for reflection on changes in the relationship between art and politics that arose in the process of democratic change.

transl. Małgorzata Leśniak

\section{Streszczenie}

Między rytuałami pogrzebowymi a mobilizacjami protestacyjnymi. Sposoby uprawiania sztuki i polityki w okresie ostatniej cywilno-wojskowej dyktatury argentyńskiej

W ramach badań, które przeprowadziłem na temat aktywizmu i eksperymentów teatralnych w najnowszej historii Argentyny, zastanawiam się nad sposobami uprawiania sztuki i polityki podczas ostatniej dyktatury cywilno-wojskowej w latach 1976-1983. W tym celu skupiłem się na estetyczno-politycznej działalności Tit (Taller de Investigaciones Teatrales) i Cucaño - dwóch grup artystycznych powstałych w tym okresie odpowiednio w Buenos Aires i Rosario. Ich działalność była prowadzona w represyjnych warunkach, które naznaczyły codzienne życie w czasach terroryzmu państwowego. Jednak członkowie obu grup przeprowadzali odważne akcje uliczne, organizowali zgromadzenia teatralne i festiwale, a także publikowali nieformalne pisma, odwołując się w nich do specyficznej formy lub dyskursu retorycznego, nie zawsze mieli na celu bezpośrednią konfrontację $\mathrm{z}$ reżimem. W artykule zostały omówione rytuały pogrzebowe, które były obecne w działalności artystycznej obu grup. Pozwoliło to także na podjęcie refleksji dotyczącej zmian relacji między sztuką a polityką, które powstały w procesie demokratycznych przemian. 